\title{
IMPROVING SOLUBILITY AND DISSOLUTION OF A NATURAL PRODUCT APIGENIN VIA PREPARATION OF SOLID DISPERSION BY HOT MELT EXTRUSION
}

\author{
SOFI N. STIANI ${ }^{1,2^{*}}$, TAOFIK RUSDIANA ${ }^{1}$, ANAS SUBARNAS ${ }^{3}$
}

1Department of Pharmaceutics and Pharmaceutical Technology, Padjadjaran University, ${ }^{2}$ Pharmacy Study Program, STIKes Salsabila, Serang Banten, Indonesia, ${ }^{3}$ Department of Pharmacology and Clinical Pharmacy, Padjadjaran University

Email: sofia240586@gmail.com

Received: 24 Sep 2020, Revised and Accepted: 15 Oct 2020

\begin{abstract}
Objective: Hot Melt Extrusion (HME) is one of the techniques for preparing a solid dispersion hydrophilic excipient known as a no solvents practical method to increase the solubility of drugs. Apigenin (APG) has properties that thermal stable with melting point $345-350{ }^{\circ} \mathrm{C}$ but very low solubility in the water around $1,35 \mu \mathrm{g} / \mathrm{ml}$. The polymer is stable in the HME method are Soluplus and Kollidon VA 64. The study aims to optimize the kind of polymer in HME formulae to improve the solubility and dissolution rate of apigenin by solid dispersion using hot-melt extrusion.
\end{abstract}

Methods: Apigenin $10-50 \% \mathrm{w} / \mathrm{w}$ and Kollidon $₫$ VA 64 or Soluplus $\AA$ and combination of Kollidon $₫$ VA 64 and Soluplus $®$ were mixed, and the resulting blends extruded using a twin-screw extruder (Teach-Line ZK25T). Characterization of apigenin extrudates conducted using scanning electron microscopy, thermogravimetric analysis, differential scanning calorimetry, Fourier transform infrared spectroscopy, powder X-ray diffractometry, and dissolution.

Results: Solubility studies presented enhancement in apigenin of 10\%/Soluplus $® 90 \%$; $10 \%$ w/w apigenin/Kollidon $囚 V A$ 64 (90\%); and 33,3\%

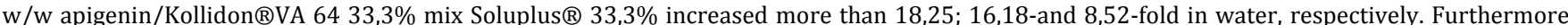
dissolution studies showed enhancement in apigenin percent release of $10 \% /$ Soluplus $® 90 \% ; 10 \% \mathrm{w} / \mathrm{w}$ apigenin/Kollidon®VA 64 90\%; and 33,3\% w/w apigenin/Kollidon ${ }^{\circledR V A} 64$ 33,3\% mix Soluplus ${ }^{\circledR} 33,3 \%$ tablet apigenin HME up to 34,29\%; 69,75\% and 30,69\%, respectively.

Conclusion: The formulation of $10 \% \mathrm{w} / \mathrm{w}$ Apigenin and $90 \%$ Soluplus ${ }^{\circledR}$ using hot-melt extrusion able to increase water solubility approximately 18,25 -fold than raw material apigenin.

Keywords: Apigenin, Solid dispersion, Solubility, Hot melt extrusion

(C) 2021 The Authors. Published by Innovare Academic Sciences Pvt Ltd. This is an open access article under the CC BYlicense (https://creativecommons.org/licenses/by/4.0/) DOI: https://dx.doi.org/10.22159/ijap.2021.v13s3.10 Journal homepage: https://innovareacademics.in/journals/index.php/ijap

\section{INTRODUCTION}

Apigenin is a phytochemical compound that contained in some fruits, herbs, and vegetables. The main source of Apigenin is celery (Apium graveolens L), parsley, and chamomile [1]. Apigenin (5,7,4-trihydroxy flavone) corresponds to the subclass of flavones, and it is present in minimal amounts in food [2]. The previous research showed that APG with dose $4,8 \mathrm{mg} / \mathrm{kg}$ BW has potential as anticalculi [3]. Although APG has much practical use, it faces an obstacle in the formulation because of limited solubility, especially when it is used for oral administration. APG solubility in water is insoluble $0.00135 \mathrm{mg} / \mathrm{ml}$ [4]. APG categorized as BSC (Biopharmaceutical Classification system) class II, which has high permeability but low solubility and weak acid with the solubility of $1.43,1.56$, and $2.16 \mu \mathrm{g} / \mathrm{ml}$ in $\mathrm{pH} 1.0,6.8$, and 7.5 , respectively [5]. Apigenin solubility is influenced by $\mathrm{pH}$, particle size, selected solvent, and temperature; hence it needs to overcome different barriers for successful apigenin delivery [6]. Many techniques used for improving chemical and physical properties including particle size reduction, micronization, physical modifications, nanosuspension, modification of crystal habit such as, pseudo polymorphs, polymorphs, salt formation, complexation, solubilization, and use of cyclodextrins which can enhance the solubility and dissolution rate of insoluble drug and solid dispersion [7]. However, limited studies concerning the application of these techniques apigenin for examples apigenin nanocrystals using supercritical antisolvent process [8], inclusion complex of apigenin-hydroxypropyl- $\beta$-cyclodextrin by using supercritical antisolvent process [9], cocrystal of apigenin [10], apigenin in binary $\{$ Transcutol $囚+$ water $\}$ mixtures [11], Formulation and characterization of an apigenin-phospholipid phytosomes (APLC) [12], design and evaluation of a self-micro emulsifying drug delivery system for apigenin [13], improved solubility and oral bioavailability of apigenin via soluplus/pluronic f127 binary mixed micelles system [14], preparation and in vitro evaluation of apigenin loaded lipid nanocapsules [15]. Lack of several methods than HME are difficult to scale up the process, and requires a lot of organic solvents [16].
The solid dispersion has become an established solubilization technology for poorly water-soluble drugs, and it is the most promising successful in enhancing solubility. Since a solid dispersion is a modifier, a drug-polymer two-component system, the drug-polymer interaction is the determining factor in its design and performance [17]. Some of the practical aspects to consider for the preparation of solid dispersions, such as methods of physicochemical characterization, selection of carrier, along with an insight into the molecular arrangement of drugs in solid dispersions [18]. Dispersion techniques in carriers can conduct by hot spin mixing, co-evaporation, co-precipitation, freeze-drying, spray drying, and hot-melt extrusion (HME) [19]. The technique still rare in Indonesia is HME. Recently, many pharmacies material had prepared their solid dispersion using HME. However, in that consideration, no HME technique applies an APG. HME is an efficient technology for producing solid molecular distributions with considerable advantages over solvent-based processes such as spray drying and co-precipitation [20]. Spray drying has a report to enhance the solubility and dissolution of Ibuprofen microparticle [21]. Advantage of HME is superior to other techniques because the process is easy, no solvent is required, enhance dissolution rate for solid dispersion, mask the taste, and controlling and modifying drug release [22]. APG suitable for HME method using high energy because it has a high melting point $345-350^{\circ} \mathrm{C}[23]$.

This study aimed to improve the solubility and dissolution of Apigenin. Two polymeric carriers Soluplus $\AA$, polyvinylpyrrolidoneco-vinyl acetate 64 (Kollidon ${ }^{\circledR}$ VA 64), were selected via the hotmelt extrusion process to investigate the solubility and dissolution of apigenin. The matrix use soluplus ${ }^{\circledR}$ and Kollidon ${ }^{\circledR}$ VA 64 and is mixed due to show the best and most suitable polymer for HME and has thermoplastic behavior, proper transition glass (Tg), high degradation temperature, and low toxicity [24].

\section{MATERIALS AND METHODS}

\section{Materials}

Apigenin for the standard purchase from Sigma-Aldrich, apigenin row material (Hefei Dielegance Biotechnology Co., Ltd), Soluplus ${ }^{\circledR}$, 
and Kollidon ${ }^{\circledR}$ VA 64 (BASF-Megasetia), reagents used in this study was of analytical grade, twin-screw extruder (Teach-Line ZK25T) in Polytechnique STMI Jakarta.

\section{Methods}

\section{HME preparation}

Hot Melt Extrusion Apigenin $10-50 \%$ w/w and Soluplus ${ }^{\circledR}$, Kollidon $^{\circledR}$ VA 64 (table 1) mix using a mixer (IKA EUROSTAR) for $10 \mathrm{~min}$. The resulting concrete mixture blends extruded using a twin-screw extruder (Teach-Line ZK25T) at the screw speed of $100 \mathrm{rpm}$, at a temperature $140{ }^{\circ} \mathrm{C}$ and $180{ }^{\circ} \mathrm{C}$. All extrudates were milled and sieved through an ASTM 35 mesh to obtain a uniform particle size [25].

\section{Thermogravimetric analysis}

Thermogravimetric analysis (TGA) perform for apigenin, Soluplus ${ }^{\circledR}$, Kollidon ${ }^{\circledR}$ VA 64 , and mixed to evaluate their stability at the extrusion temperatures. Approximately $10-15 \mathrm{mg}$ of apigenin, polymers, as well as physical mixtures, was heated from $30{ }^{\circ} \mathrm{C}$ to $300^{\circ} \mathrm{C}$ at a heating rate of $20^{\circ} \mathrm{C} / \mathrm{min}$ (HITACHI, STA7300) [25].

Table 1: Apigenin composition for HME

\begin{tabular}{llll}
\hline Formulation & Apigenin (\%) & Soluplus® & Kollidon® VA 64 \\
\hline F1 & 10 & 90 & - \\
F2 & 20 & 80 & - \\
F3 & 40 & 60 & - \\
F4 & 10 & - & 90 \\
F5 & 20 & - & 80 \\
F6 & 40 & - & 60 \\
F7 & 50 & 25 & 25 \\
F8 & 33,3 & 33,3 & 33,3 \\
F9 & 20 & 40 & 40 \\
F10 & 14,2 & 42,9 & 42,9 \\
\hline
\end{tabular}

\section{Differential scanning calorimetry}

Differential scanning calorimetry (DSC) studies obtained using Perkin Elmer Pyris 1 DSC equipped with Pyris manager software (PerkinElmer Life and Analytical Sciences). Approximately 2-4 mg of apigenin, extrudates were heated from $30^{\circ} \mathrm{C}$ to $400{ }^{\circ} \mathrm{C}$ at a heating rate of $10^{\circ} \mathrm{C} / \mathrm{min}[4]$

\section{$\mathrm{X}$-ray diffraction (XRD)}

The samples were analyzed by XRD pattern using an X-ray powder diffractometer with a rotating anode (Philips, PW 2213/30) and Cu $\mathrm{Ka} 1$ radiation generated at $30 \mathrm{~mA}$ and $50 \mathrm{kV}$. The scanning rate was $5^{\circ} / \mathrm{min}$ from 5 to $60^{\circ}[26]$.

\section{Scanning electron microscopy}

The morphology and physical state of the extrudates evaluated using Scanning electron microscopy (SEM) analysis. Samples were mounted on adhesive carbon pads placed on aluminum and were sputter-coated with gold using ion sputter (HITACHI MC1000) in a high vacuum evaporator. HITACHI SU3500 scanning electron microscope operating (SEM) at an accelerating voltage of $10 \mathrm{kV}$ used for imaging [25].

\section{Fourier transforms infrared spectroscopy}

Fourier transforms infrared spectroscopy (FTIR) spectra of apigenin, polymeric carriers, physical mixtures, as well as extrudates were performed using IR prestige-21 SHIMAZU FTIR. Apigenin $5 \mathrm{mg}$ of each sample was mixed with $200 \mathrm{mg}$ KBR and compressed into pellet and the scanning range was $400-4000 \mathrm{~cm}^{-1}$, and the resolution was $1 \mathrm{~cm}^{-1}$ [25].

\section{Solubility test}

The solubility was determined at saturated water for formulations F1-F10 and optimum formula as well as pure apigenin. Samples equivalent to approximately $100 \mathrm{mg}$ of apigenin each put into a flask containing $100 \mathrm{ml}$ of aquadest shaken in $24 \mathrm{~h}$. Then filtered and diluted using aquadest until $10 \mathrm{ppm}$ by adding ethanol $96 \%$. A sample volume of $1 \mathrm{ml}$ collected and detected with spectrophotometer (SPECORD 200) wavelength for apigenin detection set at $\langle\mathrm{m}$ ax $336 \mathrm{~nm} \quad[10,25]$.

\section{In vitro drug release}

A tablet with $8 \%$ primogel equivalent to $58,08 \mathrm{mg}$ apigenin of each extrudate as well as pure apigenin and in vitro drug release profiles run using a USP type II dissolution apparatus. The used dissolution medium was $900 \mathrm{ml}$ of $0.4 \%$ SDS maintained at $37{ }^{\circ} \mathrm{C}$. A sample volume of $5 \mathrm{ml}$ taken at $5,10,15,30,45,60,120$ mfiltered, and analyzed using a spectrophotometer; then, $5 \mathrm{ml}$ of fresh dissolution medium was added back to the dissolution vessel at each time point to maintain the volume [26].

\section{RESULTS AND DISCUSSION}

All formulation conducted processing temperatures, TGA data showed no decrease in sample weight, decomposition held up $250{ }^{\circ} \mathrm{C}$, which indicated that all formulations in the study were stable under all applied extrusion temperatures is $140^{\circ} \mathrm{C}$ can be seen on fig. 1 .

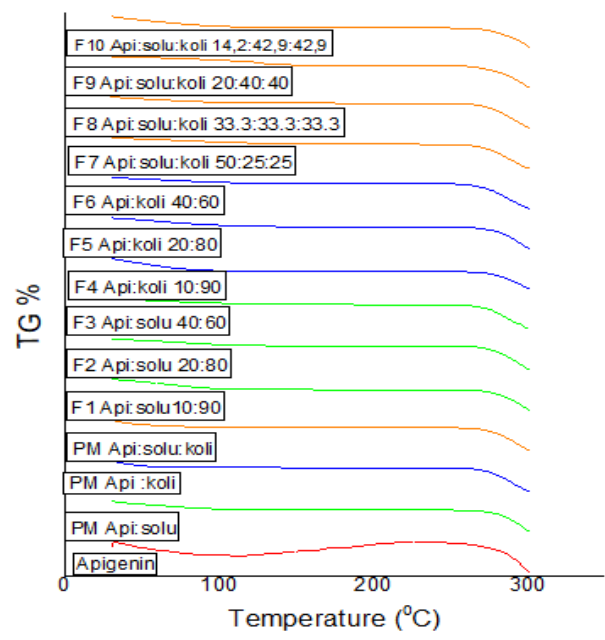

Fig. 1: TGA all formulation

XRD data showed pure apigenin, the physical mixture is crystalline, but with HME change crystallin form to amorf so that solubility can increase, all the extrudates showed in fig. 2.

The solubility of apigenin enhance after prepared by HME, formula 1 , formula 4 , and formula 8 is the highest solubility (table 2). In this research, we optimize temperature and screw with hot melt extrusion for three formulations are F1 apigenin $10 \%$ and Soluplus ${ }^{\circledR}$ 90\%; F2 apigenin 10\% and Kollidon ${ }^{\circledR}$ VA 64 90\%; and F3 apigenin 33,3\%, Soluplus ${ }^{\circledR} 33,3 \%$, mixed Kollidon $®$ VA 64 33,3\%. 


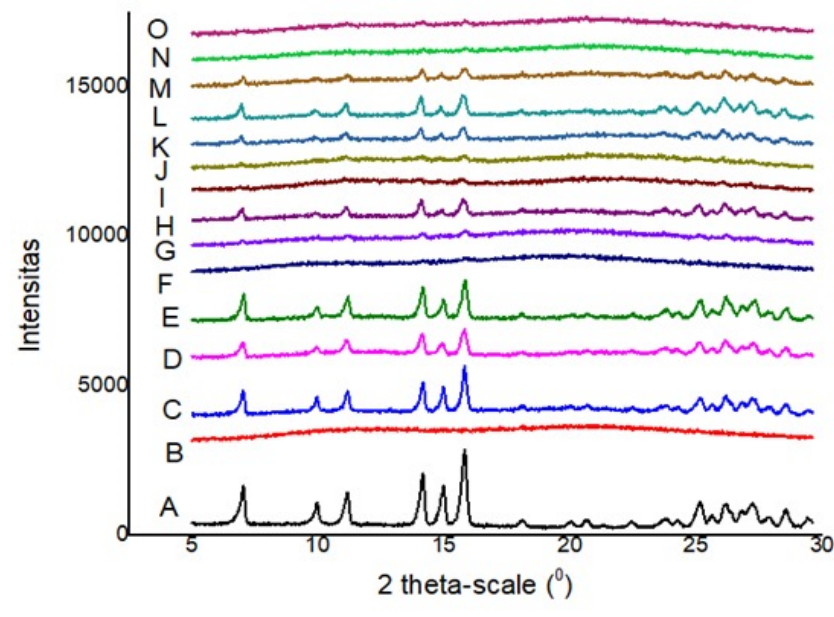

Fig. 2: PXRD (a) pure apigenin, (b) Soluplus $₫$ and Kollidon ${ }^{\circledR}$ VA64, (c) PM APG-solu, (d) PM APG-koli, (e) PM APG-solu-koli, (f) $10 \%$ w/w APG/Soluplus $® 90 \%$, (g) $20 \%$ w/w APG/Soluplus $\AA^{8} 80 \%$, (h) 40\% w/w APG/Soluplus $₫ 60 \%$, (i) $10 \%$ w/w APG/Kollidon ${ }^{\circledR}$ VA64 (90\%), (j) $20 \%$ w/w APG/Kollidon ${ }^{\circledR}$ VA64 (80\%), (k) 40\% w/w APG/Kollidon® VA64 (60\%), (1) 50\%w/w APG-solu 25\%-koli 25\%, (m) 33,3\%w/w APG-solu 33,3\%-koli 33,3\%, (n) 20\%w/w APG-solu 40\%-koli 40\%, (o) 14\%w/w APG-solu 43\%-koli 43\%
Table 2: Separated solubility apigenin in water*

\begin{tabular}{ll}
\hline Sample & Dissolve concentration \pm SD $(\mathbf{m g} / \mathbf{l})$ \\
\hline Apigenin & $1,0109 \pm 0,0015$ \\
Formula 1 & $17,716 \pm 0,0011$ \\
Formula 2 & $4,7031 \pm 0,001$ \\
Formula 3 & $2,4682 \pm 0,001$ \\
Formula 4 & $16,084 \pm 0,0061$ \\
Formula 5 & $7,7754 \pm 0,0015$ \\
Formula 6 & $8,9772 \pm 0,003$ \\
Formula 7 & $3,8494 \pm 0,0030$ \\
Formula 8 & $9,4122 \pm 0,0058$ \\
Formula 9 & $6,5846 \pm 0,0032$ \\
Formula 10 & $8,5639 \pm 0,0055$
\end{tabular}

${ }^{*}$ Avg $\pm \%$ in $\mathrm{mg} / \mathrm{l}$ deviation, $\mathrm{n}=3$

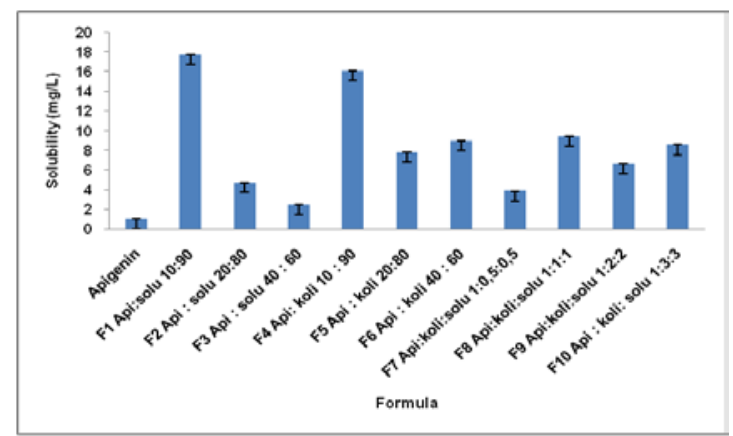

Fig. 3: Solubility of apigenin

Table 3: Processing parameters for HME

\begin{tabular}{|c|c|c|c|}
\hline Formulation & Temperature $\left({ }^{\circ} \mathrm{C}\right)$ & Screw speed (rpm) & Extrudate image \\
\hline \multirow[t]{5}{*}{ Apigenin: Soluplus 10: 90} & 110 & $5-100$ & no extrudate \\
\hline & 120 & $5-100$ & no extrudate \\
\hline & 130 & $5-100$ & no extrudate \\
\hline & 140 & $5-90$ & Little bit extrudate \\
\hline & 140 & 100 & \\
\hline \multirow[t]{5}{*}{ Apigenin: Kollidon VA 64 10: 90} & 110 & $5-100$ & no extrudate \\
\hline & 120 & $5-100$ & no extrudate \\
\hline & 130 & $5-100$ & no extrudate \\
\hline & 140 & $5-90$ & \\
\hline & 140 & 100 & \\
\hline \multirow[t]{5}{*}{ Apigenin: Soluplus: Kollidon VA 64 33,3\%:33,3\%: 33,3\% } & 110 & $5-100$ & no extrudate \\
\hline & $120-170$ & $5-100$ & no extrudate \\
\hline & 180 & 100 & \\
\hline & 190 & 100 & \\
\hline & 210 & 100 & \\
\hline
\end{tabular}

The hot-melt extrusion process carried out using a twin-screw extruder (Teach-Line ZK25T) standard screw coffiguration used in this study, which consists of five conveying zones and two mixing zones (fig. 4). 


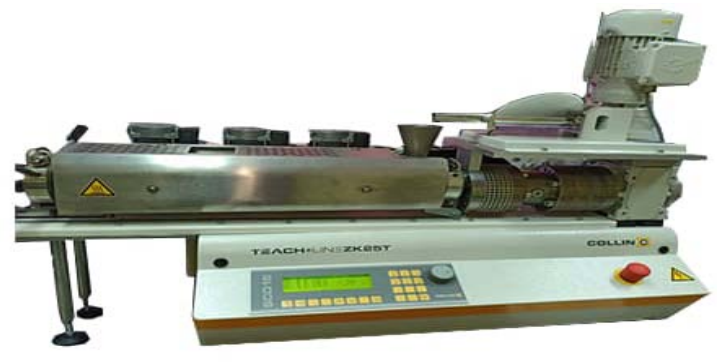

Fig. 4: Twin screw extruder

The HME processing conditions for screw speed and extrusion temperatures are stable results good extrudate was greenish-yellow, transparent, and brittle in $140{ }^{\circ} \mathrm{C}$ and $100 \mathrm{rpm}$ for polymer Soluplus ${ }^{\circledR}$ and Kollidon ${ }^{\circledR}$ separately although mixed Soluplus ${ }^{\circledR}$ and Kollidon ${ }^{\circledR}$ give the resulting extrudate was brown, brittle, not transparent, opaque in $180{ }^{\circ} \mathrm{C}$ and $100 \mathrm{rpm}$. All extrudates were milled using a coffee grinder and sieved to obtain a uniform particle size (table 3).

Formula 1 has solubility $18,455 \mu \mathrm{g} / \mathrm{ml}$, apigenin $1,011 \mu \mathrm{g} / \mathrm{ml}$. Formula 1 has a 18,25-fold solubility increase compare to apigenin without HME, and it can see in fig. 5 .

Table 4: Separated solubility apigenin in water for optimum formula

\begin{tabular}{ll}
\hline Sample & Dissolve concentration $(\mathbf{m g} / \mathbf{l}) \pm$ SD \\
\hline Apigenin & $1,011 \pm 0,0249$ \\
F1 & $18,455 \pm 0,0652$ \\
F2 & $16,362 \pm 0,0188$ \\
F3 & $8,618 \pm 0,0282$ \\
PM F1 & $6,100 \pm 0,0524$ \\
PM F2 & $0,212 \pm 0,0094$ \\
PM F3 & $0,456 \pm 0,0188$ \\
\hline
\end{tabular}

${ }^{*} \mathrm{Avg} \pm \%$ in $\mathrm{mg} / \mathrm{l}$ deviation, $\mathrm{n}=3$

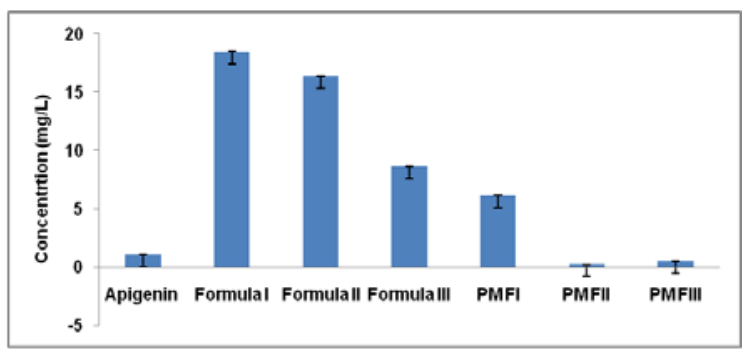

Fig. 5:The solubility of apigenin in the optimum formula

\section{Fourier transforms infrared spectroscopy (FTIR)}

There is a shift in the spectrum but does not form new bonds, indicating there any chemical change in solid dispersion. The loss of some peak in apigenin-like polymers means that solid dispersion has formed (fig. 6).

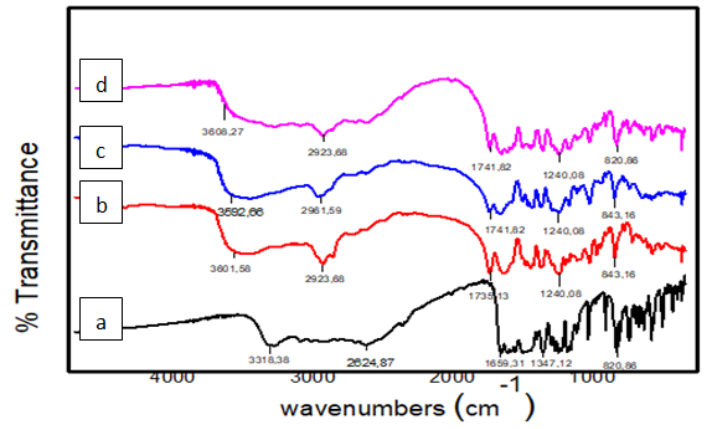

Fig. 6: (a) Fourier transforms infrared spectroscopy (FTIR) spectra of apigenin, (b) $10 \%$ w/w APG with Soluplus $90 \%$, (c) $10 \%$ w/w APG with kollidon 90\%, (d) 33,3\% w/w APG mixed soluplus $33,3 \%$ and kollidon $33,3 \%$

DSC result results show that Apigenin has an endothermic peak up $347,76^{\circ} \mathrm{C}$ means a crystalline structure. In contrast, others do not have sharp peaks that apigenin wit HME is molecularly dispersed into the pores of polymer and possibility amorphous state due to solubility increase. Alternatively, all the extrudates showed the absence of crystalline melting peaks in DSC data (fig. 7).

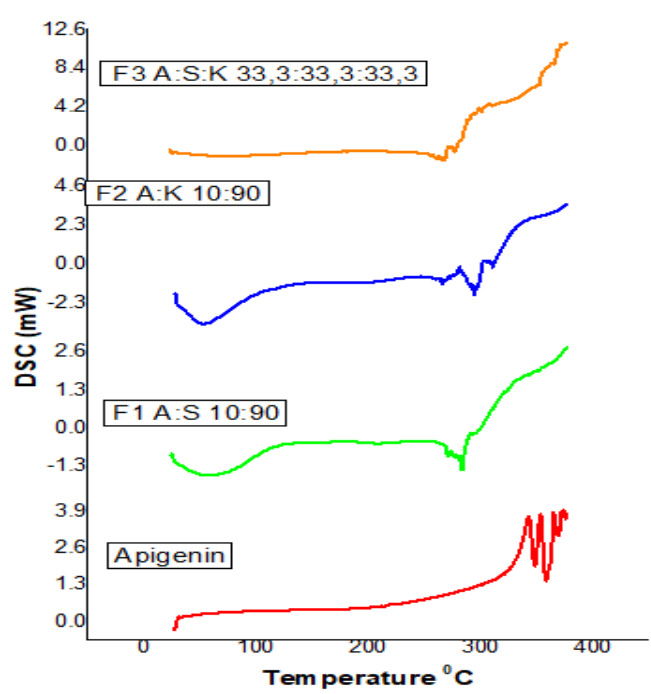

Fig. 7: Differential scanning calorimetry of extrudates

Scanning electron microscopy images showed the absence of crystals in $10 \% \mathrm{w} / \mathrm{w}$ apigenin/Soluplus and kollidon indicating that apigenin was dispersed in the Soluplus and in the kollidon polymer carrier as an amorphous, but when apigenin, soluplus mixed by kollidon with the same comparison still have image crystallin. However, crystals were evident in all other formulations with different ratios. Below are pictures of apigenin before and after HME (fig. 8).

The formula I have particle size smallest than the others is $685,1 \mathrm{~nm}$; the smaller particle size can increase the solubility of the drug.

Table 5: Drug loading and particle size of apigenin

\begin{tabular}{lll}
\hline Formula & Drug loading (\%) & (Particle size) (nm) \\
\hline Apigenin & - & $1743.33 \pm 15.63$ \\
F1 (Apigenin: Soluplus 10: 90) & $90 \%$ & $685.1 \pm 8.77$ \\
F2 (Apigenin: Kollidon VA 64 10: 90) & $96 \%$ & $700.33 \pm 13.09$ \\
F3 (Apigenin: Soluplus: Kollidon VA 64: 33.3:33.3:33.3) & $78.31 \%$ & $6222.67 \pm 337.7$ \\
\hline
\end{tabular}

DrugLoading \%, particle size in nm; Avg \pm deviation, $n=3$ 


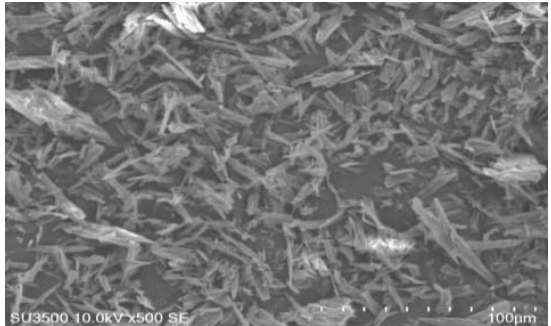

(a)

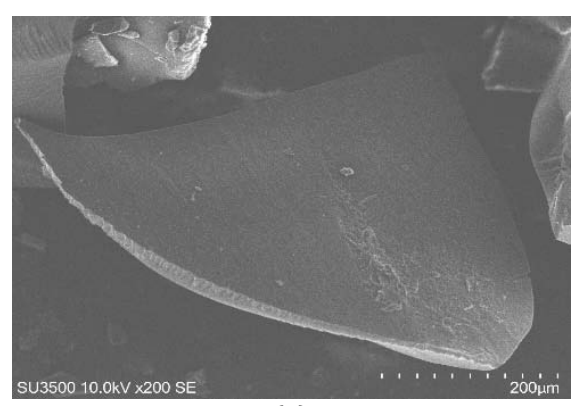

(e)

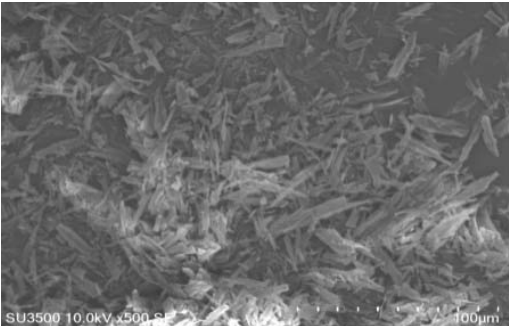

(b)

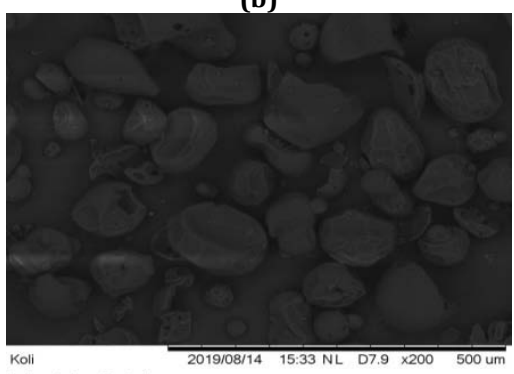

(d)

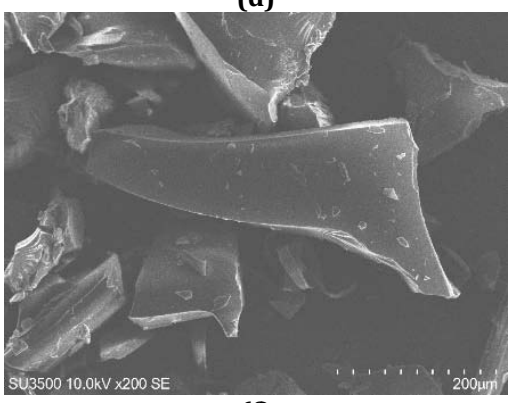

(f)

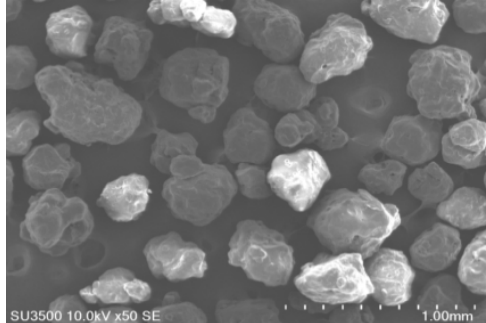

(c)

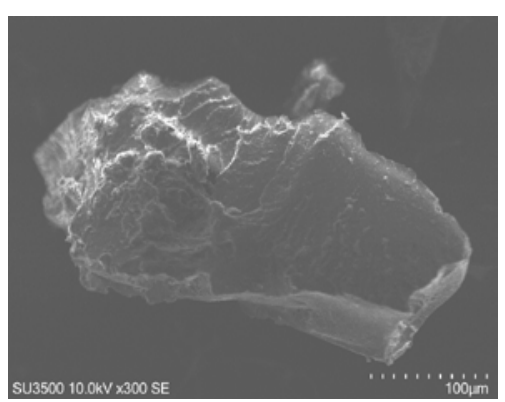

(g)

Fig. 8: SEM image (a) pure apigenin, (b) Physical mixture, (c) Soluplus $₫$, (d) Kollidon® VA64, (e) 10\% w/w apigenin/Soluplus $₫ ~ 90 \%$, (f) $10 \% \mathrm{w} / \mathrm{w}$ apigenin/Kollidon $₫$ VA64, (g) 33,3\% w/w apigenin/Soluplus $₫ 33,3 \%$ mixed by $33,3 \%$ Kollidon $₫$ VA64

Dissolution studies demonstrated enhancement in apigenin percent release of $10 \% /$ Soluplus $₫ 90 \%$; $10 \% \mathrm{w} / \mathrm{w}$ apigenin/Kollidon $® V A \quad 64 \quad 90 \% ; \quad$ and $33,3 \% \quad w / w$
apigenin/Kollidon ${ }^{\circledR}$ VA $64 \quad 33,3 \%$ mix Soluplus ${ }^{\circledR} \quad 33,3 \%$ tablet apigenin HME up to $34,29 \% ; 69,75 \%$ and $30,69 \%$, respectively (fig. 9).

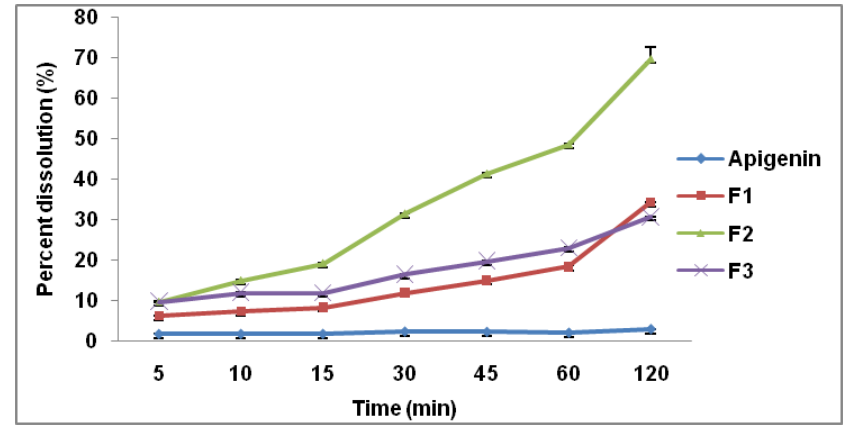

Fig. 9: In vitro drug release HME tablet of Apigenin, $\diamond$ pure Apigenin; $\square$ Formulae $1 ; \Delta$ Form ulae 2;><Formulae 3

\section{CONCLUSION}

Solid dispersion technique by Hot Melt Extrusion (HME) can improve the solubility and dissolution of Apigenin. Formula 1 with $10 \% \mathrm{w} / \mathrm{w}$ Apigenin $/ 90 \%$ soluplus $^{\circledR}$ is the best formula in this research can increase the 18, 25-fold solubility of Apigenin in water.

\section{ACKNOWLEDGMENT}

We would like to thank the minister of the ministry of research, technology, and higher education for supporting the funding of this research through the doctoral grant 2018 program; we would like to thank Politeknik STMI Jakarta for supporting equipment twin screw extruder.

\section{FUNDING}

This research is supported by Universitas Padjadjaran, Bandung Sumedang Indonesia, and the ministry of research, technology, and higher education Indonesia.

\section{AUTHORS CONTRIBUTIONS}

All the authors contributed equally. 


\section{CONFLICTS OF INTERESTS}

There are no conflicts of interest.

\section{REFERENCES}

1. Tang D, Chen K, Huang L, Li J. Pharmacokinetic properties and drug interactions of apigenin, a natural flavone. Expert Opin Drug Metab Toxicol 2017;13:323-30.

2. Sharafzadeh S, Alizadeh O. German and roman chamomile. J Appl Pharm Sci 2011;1:1-5.

3. Stiani SN, Fillah SM, Hanindhiya F, Subarnas A, Rusdiana T. Anticalculi activity of apigenin and celery (Apium graveolens $\mathrm{L}$.) extract in rats induced by ethylene glycol-ammonium chloride. J Pharm Bioallied Sci 2019;11:556-61.

4. Li B, Robinson DH, Birt DF. Evaluation of properties of apigenin and $[\mathrm{G}-3 \mathrm{H}]$ apigenin and analytic method development. J Pharm Sci 1997;86:721-5.

5. Zhang J, Liu D, Huang Y, Gao Y, Qian S. Biopharmaceutics classification and intestinal absorption study of apigenin. Int J Pharm 2012;436:311-7.

6. Altamimi MA, Eljayat M, Alshehri M, Mohsin K, Ibrahim A, Maenazal A, et al. Utilizing spray drying technique to improve oral bioavailability of apigenin. Adv Powder Technol 2018;29:1676-84.

7. Dogra X, Dhyani A, Juyal D. Solid dispersion. Int J Pharm Sci Lett 2015;5:593-8.

8. Zhang J, Huang Y, Liu D, Gao Y, Qian S. Preparation of apigenin nanocrystals using supercritical antisolvent process for dissolution and bioavailability enhancement. Eur J Pharm Sci 2013;45:740-7.

9. Huang $\mathrm{Y}, \mathrm{Zu} \mathrm{Y}$, Zhao $\mathrm{X}, \mathrm{Wu} \mathrm{M}$, Feng $\mathrm{Z}$, Deng $\mathrm{Y}$, et al. Preparation of inclusion complex of apigenin-hydroxypropyl$\beta$-cyclodextrin by using supercritical antisolvent process for dissolution and bioavailability enhancement. Int J Pharm 2016;512:921-30.

10. Ma XQ, Zhuang C, Wang BC, Huang YF, Chen $Q$, Lin $N$. Cocrystal of apigenin with higher solubility. Enhanced oral bioavailability and anti-inflammatory effect cryst. Growth Des 2019;19:5531-7.

11. Shakeel F, Haq N, Alshehri S. Solubility determination and thermodynamic data of apigenin in binary \{Transcutol ${ }^{\circledR}+$ water $\}$ mixtures. Ind Crops Prod 2018; 116:56-63.

12. Telange DR, Patil AT, Pethe AM, Fegade H, Anand S, Dave VS. Formulation and characterization of an apigenin-phospholipid phytosome (APLC) for improved solubility, in vivo bioavailability, and antioxidant potential. Eur J Pharm Sci 2017;108:36-49.

13. Zhao L, Zhang L, Meng L, Wang J, Zhai G. Design and evaluation of a self-microemulsifying drug delivery system for apigenin. Drug Dev Ind Pharm 2013;39:662-9.

14. Zhang Z, Cui C, Wei F, Lv H. Improved solubility and oral bioavailability of apigenin via Soluplus/Pluronic F127 binary mixed micelles system. Drug Dev Ind Pharm 2017;43:1276-82.

15. Ding B, Chen H, Wang C, Zhai Y, Zhai G. Preparation and in vitro evaluation of apigenin loaded lipid nanocapsules. J Nanosci Nanotechnol 2013;13:6546-52.

16. Gao N, Guo M, Fu Q, He Z. Application of hot-melt extrusion to enhance the dissolution and oral bioavailability of oleanolic acid. Asian J Pharm Sci 2017;12:66-72.

17. Huang Y, Dai WG. Fundamental aspects of solid dispersion technology for poorly soluble drugs. Acta Pharm Sin B 2014;4:16-25.

18. Dhirendra K, Lewis S, Udupa N, Atin K. Solid dispersions: a review. Pak J Pharm Sci 2009;22:234-46.

19. Stiani SN, Rusdiana T, Subarnas A. Enhancing dissolution and bioavailability of purely water-insoluble natural compounds by solid dispersion with hot-melt extrusion technique. J Global Pharma Technol 2018;10:139-51.

20. Singhal S, Lohar VK, Arora V. Hot melt extrusion technique. Webmed Central Pharm Sci 2011;2:1-20.

21. Rachmaniar R, Panatarani C, Joni IM, Abdasah M, Rusdiana T Enhancement of solubility and dissolution of ibuprofen microparticle prepared by ultrasonic spray drying. Marmara Pharm J 2017;21:783-92.

22. Chokshi R, Zia H. Hot-melt extrusion technique: a review. Iran J Pharm Res 2004;3:3-16.

23. Yulianto AN, Rusdiana T, Muchtaridi M, Subarnas A. Validation of UV-Vis spectrophotometry methode for analysis of apigenin in celery extract (Apium graveolens L.). Pharmaciana 2017;72:159.

24. Kolter M, Karl K. Suitability of plasticized polymers for hot-melt extrusion. Ex Act For Pharma Ing Serv 2010;24:2-6.

25. Ashour EA, Majumdar S, Alsheteli A, Alsulays B, Ashehri S, Feng $\mathrm{X}$, et al. Hot melt extrusion as an approach to improve solubility, permeability and oral absorption of a psychoactive natural product, piperine. J Pharm Pharmacol 2016;68:989-98.

26. Yannian H, Zhao X, Zu Y, Wang L, Deng Y, Wu M, et al. Enhanced solubility and bioavailability of apigenin via preparation of solid dispersions of mesoporous silica nanoparticles. Iran J Pharm Res 2019;18:168-82. 